\title{
European drought trends
}

\section{Gudmundsson and S. I. Seneviratne}

Institute for Atmospheric and Climate Science, ETH Zurich, Universitaetstrasse 16, 8092 Zurich, Switzerland

Correspondence to: L. Gudmundsson (lukas.gudmundsson@env.ethz.ch)

Received: 14 April 2015 - Accepted: 14 April 2015 - Published: 11 June 2015

\begin{abstract}
Recent climate projections suggest pronounced changes in European drought frequency. In the north, increased precipitation volumes are likely to reduce drought occurrence, whereas more frequent droughts are expected for southern Europe. To assess whether this pattern of changes in drought frequency can already be identified for the past decades, we analyse trends in a recently developed pan-European drought climatology that is based on the Standardized Precipitation Index (SPI). The index is derived on multiple time scales, ranging from 1 to 36 months, which allows the assessment of trends in both short term and multi-year droughts. Trends are quantified using the Theil-Sen trend estimator combined with an extension of the Mann-Kendal test $(p<0.05)$ that accounts for serial correlation. Field significance is assessed on the basis of techniques that control the false discovery rate in a multiple testing setting. The trend analysis indicates that changes in drought frequency are more pronounced on time scales of one year and longer. The analysis also reveals that there has been a tendency for decreased drought frequency in northern Europe in the past decades, whereas droughts have likely become more frequent in selected southern regions.
\end{abstract}

\section{Introduction}

Climate change projections repeatedly indicate that water availability in Europe will change as a consequence of anthropogenic greenhouse gas emission. Overall, model simulations suggest that there will be a tendency of wetting in the north of the continent, whereas more frequent droughts are to be expected in the south (Orlowsky and Seneviratne, 2013). In recent years, several studies have indicated that similar spatial patterns of wetting and drying can be found in the observational record of water cycle variables, including precipitation (Klein Tank and Können, 2003) and streamflow (Stahl et al., 2010, 2012). However the identified signals are weak. With respect to drought analysis, Bordi et al. (2009) found that strong inter-annual variability of pan-European drought indicators can render a clear identification of drought trends difficult. This is also reflected in the conclusion of a recent synthesis report on the influence of climate change on extremes, which states that there is only medium confidence of an increasing drought hazard in southern Europe (Seneviratne et al., 2012).

This study aims at reassessing the patterns of changes in European drought frequency, by analysing the most com- prehensive observed precipitation grids for Europe (Haylock et al., 2008). Drought is quantified using the Standardized Precipitation Index (SPI, McKee et al., 1993; Gudmundsson and Seneviratne, 2015) that allows assessing changes in the occurrence frequency of precipitation amounts on different time scales. Trends are quantified on a grid-cell level and the field-significance of the emerging spatial trend patterns is assessed. Finally, the results are discussed with respect to past drought impacts.

\section{Data}

This study is based on the E-OBS (version 10) dataset (Haylock, 2008f), which provides comprehensive information on precipitation in Europe. The E-OBS dataset interpolates observed precipitation time series and is available at daily resolution on a $0.5^{\circ}$ grid. Prior to any other computation, the daily precipitation grid is aggregated to monthly means. For the presented study, data in the domain ranging from $12^{\circ} \mathrm{W}-$ $43^{\circ} \mathrm{E}$ and $34^{\circ} \mathrm{N}-72^{\circ} \mathrm{N}$ are considered. 


\section{Methods}

\subsection{The Standardized Precipitation Index}

Drought is quantified on the basis of the Standardized Precipitation Index (SPI, McKee et al., 1993), which has also been recommended by the WMO for drought monitoring (Hayes et al., 2010). The first step of the SPI transformation is to apply a backward looking moving average with a window length $\tau$ to the monthly precipitation series, resulting in time series of accumulated precipitation. In the literature, $\tau$ is commonly referred to as time scale. Here we consider time scales of $\tau=1, \tau=3, \tau=6, \tau=12, \tau=24$ and $\tau=36$ months. In the remainder of this paper we use the notation SPI- $\tau$ to refer to index values calculated for time-scale $\tau$. In a second step, the accumulated precipitation series are standardized for each calendar month separately. For this, data from one calendar month in a base period (e.g. all July values in 1961-1990) are assembled and a gamma-distribution is fitted to the data. Subsequently, the parameters of the gamma distribution are used to transform all the values of the corresponding months to take values of the standard normal distribution (see Stagge et al. (2015) for computational details). For this study we use the 1961-1990 base period, which is consistent with recommendation of the Expert Team on Climate Change Detection and Indices (ETCCDI, Klein Tank et al., 2009).

SPI was computed using the recently developed Standardized Climate Indices (SCI) package, which is an open source extension to the $\mathrm{R}$ software (Gudmundsson and Stagge, 2014). Details on the implementation as well as a systematic assessment of the distributional assumptions can be found in Stagge et al. (2015).

The interpretation of SPI is time-scale dependent. For example SPI-1 is suitable to analyse high frequency fluctuations in monthly precipitation whereas SPI- 3 captures precipitation anomalies accumulated over three months. This property can be used to analyse changes in the occurrence frequency of accumulated precipitation in specific seasons. For example, SPI-3 values in August capture precipitation anomalies in the three summer months (June, July and August). Similarly, SPI-12 in December captures annual precipitation anomalies.

Due to the statistical transformation SPI has also a probabilistic interpretation (Gudmundsson et al., 2014). As the index takes units of the standard normal distribution, specific values can be interpreted with respect to their exceedance frequencies. For example, if there is no trend in the underlying time series an index value smaller than -1 in a specific month is expected to occur with a probability of 0.16 (or $16 \%$ of all times). Consequently, decreasing trends in SPI indicate an increasing drought frequency, whereas increasing trends suggest a reduction of droughts.

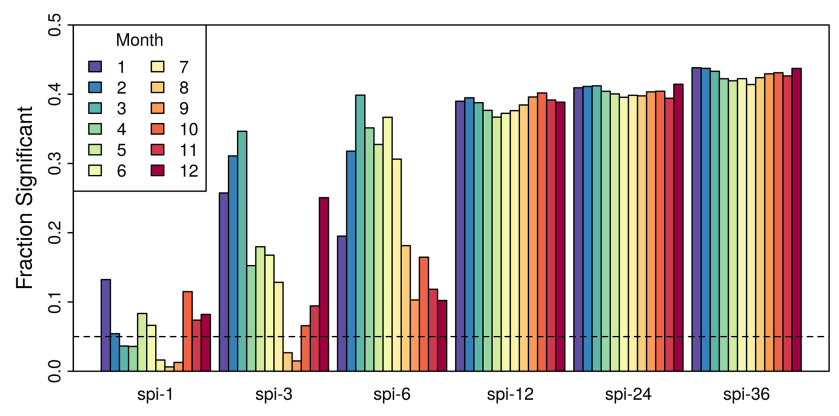

Figure 1. Fraction of grid-cells with significant $\left(\alpha_{\text {local }}<0.05\right)$ trends in SPI- $\tau$, where $\tau$ refers to the time-scale. Trends are evaluated for each calendar month separately. Field-significance is declared only if the fraction of significant grid-cells is larger than 0.05 $\left(\alpha_{\text {global }} \leq 0.05\right.$, horizontal dashed line $)$. See text for details.

\subsection{Trend analysis}

SPI trends are analysed for all considered time scales, allowing to assess changes in both short term and multi-year droughts. Potential seasonality is accounted for by performing the trend analysis for each calendar month separately.

Trends in SPI are first assessed on the grid-cell level. Trend magnitude is quantified using the Theil-Sen slope (Theil, 1950; Sen, 1968). The change rates are reported in standard deviations per decade. The significance of change is assessed using an extension of the Mann-Kendall test that accounts for serial correlation (Yue and Wang, 2004). As the trend analysis is performed for each grid-cell individually, there is an increased probability that the considered test falsely rejects the null hypothesis of no trend. To control this False Discovery Rate the $p$ values of the trend test are modified according to Benjamini and Hochberger (1995). This step is based on the recommendations of Ventura et al. (2004) and Wilks (2006) who found good performance of this procedure in a climatological context. Trends in SPI at the grid-cell level are declared significant if the modified local $p$ values fall below a critical value $\left(\alpha_{\text {local }}<0.05\right)$.

At the selected local $p$ value $5 \%$ of the trend tests are expected to falsely identify trends in the considered time series. Therefore the emerging spatial trend-pattern is only interpretable if more than $5 \%$ of the stations exhibit significant trends. In this case, the spatial trend pattern is declared fieldsignificant $\left(\alpha_{\text {global }} \leq 0.05\right)$ (Wilks, 2006).

\section{Results and discussion}

Figure 1 reports the fraction of grid cells with significant trends in SPI for all calendar months and different time scales, allowing to assess the significance of emerging spatial trend patterns. Overall there is a tendency for an increasing number of significant trends in SPI with increasing time scale. For SPI-1, only a low fraction of the grid-cells in Europe exhibits significant trends in droughts and field signifi- 


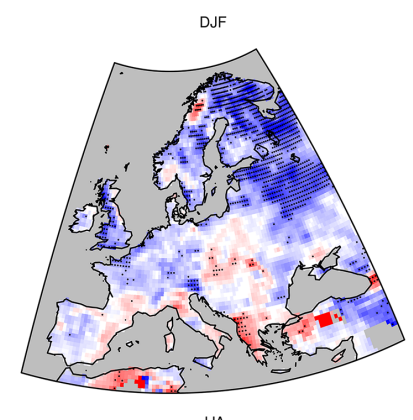

JJA

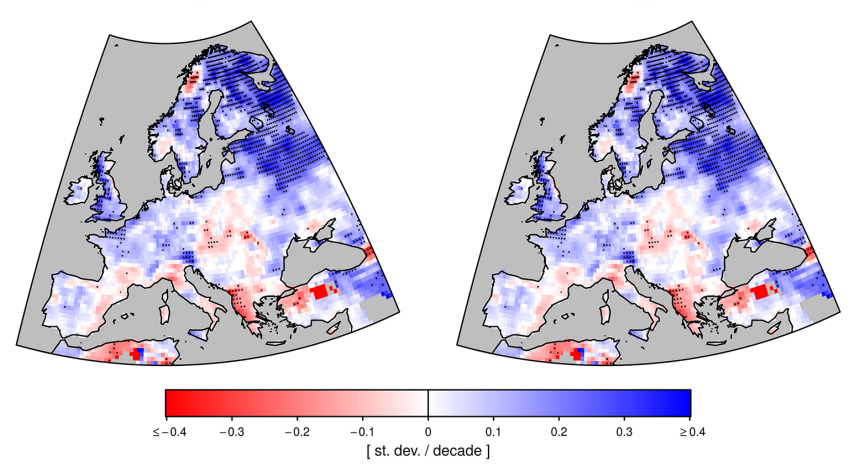

Figure 2. Seasonal patterns in SPI-3 trends. Trend patterns are evaluated for four months, of which the accumulation time covers the respective season. For Winter (DJF), SPI-3 is evaluated for the month of February, which accounts for accumulated precipitation in the three winter months (December, January, February). For Spring (MAM), SPI-3 is evaluated for the month May, accounting for accumulated precipitation in March, April and May. For Summer (JJA), SPI-3 is evaluated for August, accounting for accumulated precipitation in June, July and August. For Autumn (SON), SPI-3 is evaluated for the month of November, accounting for accumulated precipitation in September, October and November. Trends are expressed in units of standard deviations per decade. Stippling indicates local significance $\left(\alpha_{\text {local }}<0.05\right)$. Field significance is reported in Fig. 1.

cance is only found for January, February, April, May, October, November and December. The fraction of grid-cells with significant trends increases for SPI-3, for which field significance is found for all months except August and September. For SPI-6 field significance is found for all months. Interestingly, there is a pronounced seasonal pattern in the fraction of significant grid-cells for SPI with time scales ranging from 1 to 6 . In general the largest fraction of grid-cells with significant trends is found in SPI values that represent precipitation anomalies in the cold season. In the warm season, changes in drought frequency are less pronounced. This pattern changes for SPI-12, SPI-24 and SPI-36. For these time scales about $40 \%$ of the grid-cells exhibit significant changes in drought frequency irrespective of the season. The fact that trends in SPI become more significant with increasing time scales suggests that long-term changes in pan-European drought frequency may be masked by the large synoptic variability of monthly precipitation on short time scales.

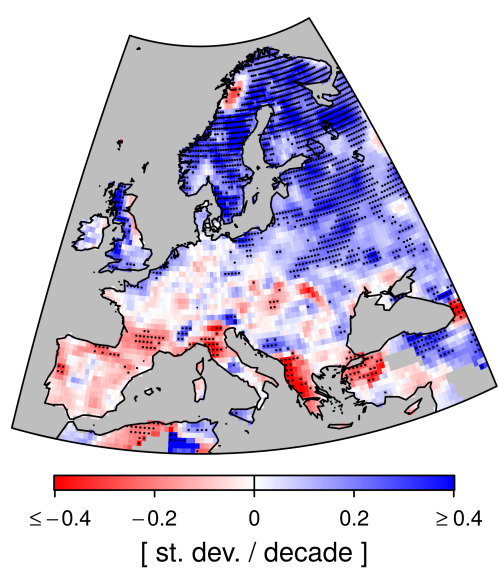

Figure 3. Spatial pattern of SPI-12 trends in December. Colours and symbols are equivalent to Fig. 2.

Figure 2 maps spatial trend patterns of SPI-3 for February, May, June and November, representing changes in drought frequency in the four seasons. For all months the fraction of grid-cells with significant trends is larger than 0.05 , indicating the field-significance of the associated spatial pattern (Fig. 1). For all four seasons significant decreases in drought frequency are found in the north of the continent. In the south only few significant changes are found. There is, however a notable tendency of an increased number of negative trends in southern Europe.

This pattern is similar for long time scales, as exemplified for the December trends in SPI-12 (Fig. 3). Again, the trend analysis reveals a pronounced decline in drought frequency in northern Europe. In central Europe no systematic changes in drought frequency are found. In Southern Europe the majority of grid cells with significant trends indicate an increase in drought frequency in the past decades. The spatial patterns of trend in SPI-24 and SPI-36 are close to the pattern shown in Fig. 3 (not shown).

In general the observed patterns of drought trends reflect previous assessments of observed changes in European water availability (Klein Tank and Können, 2003; Stahl el al., 2010, 2012), with a tendency of wetter conditions in the South and dryer conditions in the north. The similarity to drought changes in climate change projections (Orlowsky and Seneviratne, 2013) raises the question whether the observed pattern is already a consequence of anthropogenic climate change. While a detailed assessment of this question lies beyond the scope of the present study, it shall be noted that zonal precipitation trends have been formally attributed to anthropogenic greenhouse gas emissions (Zhang et al., 2007). Similarly the consistency of observed trends in winter precipitation with climate change projections has been formally demonstrated (Bhend and von Storch, 2008). However, it is also important to note that there is only a weak drying signal in Southern Europe, indicating that the emerg- 
ing signal is only barely distinguishable from internal climate variability.

\section{Summary and conclusion}

In conclusion, the presented analysis confirms previous findings suggesting that northern Europe has become wetter, whereas southern Europe has become drier in the past decades. The results imply a weak increase in drought frequency in the South of the continent, which is most pronounced on long time scales. Although the increasing drought signal in southern Europe is only weak, its similarity to projected drought changes suggests that it may be a consequence of anthropogenic climate change. This may have larger implications, as drought has been shown to significantly increase the probability of impacts on industry, farming, water supply (Blauhut et al., 2015) as well as on wild fire dynamics (Gudmundsson et al., 2014).

Acknowledgements. This research contributes to the European Union (FP7) funded project DROUGHT-R\&SPI (www.eu-drought. org/, contract no. 282769). We acknowledge the E-OBS dataset from the EU-FP6 project ENSEMBLES (http://ensembles-eu. metoffice.com) and the data providers in theECA\&D project (www. ecad.eu).

\section{References}

Blauhut, V., Gudmundsson, L., and Stahl, K. Towards panEuropean drought risk maps: quantifying the link between drought indices and reported drought impacts, Environ. Res. Lett., 10, 014008, doi:10.1088/1748-9326/10/1/014008, 2015.

Benjamini, Y. and Hochberg, Y.: Controlling the False Discovery Rate: A Practical and Powerful Approach to Multiple Testing, J. Roy. Stat. Soc., 57, 289-300, 1995.

Bhend, J. and von Storch, H.: Consistency of observed winter precipitation trends in northern Europe with regional climate change projections, Clim. Dynamics, 31, 17-28, doi:10.1007/s00382007-0335-9, 2008.

Bordi, I., Fraedrich, K., and Sutera, A.: Observed drought and wetness trends in Europe: an update, Hydrol. Earth Syst. Sci., 13, 1519-1530, doi:10.5194/hess-13-1519-2009, 2009.

Gudmundsson, L. and Stagge, J. H.: SCI: Standardized Climate Indices such as SPI, SRI or SPEIR, package version 1.0-1., available at: http://cran.r-project.org/web/packages/SCI/citation.html (last access: 22 April 2015), 2014

Gudmundsson, L., v. Loon, A. F., Tallaksen, L. M., Seneviratne, S. I., Stagge, J. H., Stahl, K., and van Lanen, H. A.: Guidelines for Monitoring and Early Warning of Drought in Europe, DROUGHT-R\&SP Technical Report No 21, available at: www.eu-drought.org, 2014.

Gudmundsson, L., Rego, F. C., Rocha, M., and Seneviratne, S. I.: Predicting above normal wildfire activity in southern Europe as a function of meteorological drought, Environ. Res.h Lett., 9, 084008, doi:10.1088/1748-9326/9/8/084008, 2014.
Gudmundsson, L. and Seneviratne, S.: A comprehensive drought climatology for Europe (1950-2013) Drought: Research and Science-Policy Interfacing, CRC Press, 31-37, doi:10.1201/b18077-7, 2015.

Hayes, M., Svoboda, M., Wall, N., and Widhalm, M.: The Lincoln Declaration on Drought Indices: Universal Meteorological Drought Index Recommended, B. Am. Meteorol. Soc., 92, 485488, 2010.

Haylock, M. R., Hofstra, N., Klein Tank, A. M. G., Klok, E. J., Jones, P. D. and New, M.: A European daily highresolution gridded data set of surface temperature and precipitation for 1950-2006, J. Geophys. Res., 113, D20119, doi:10.1029/2008JD010201, 2008.

Klein Tank, A. M. G. and Können, G. P.: Trends in Indices of Daily Temperature and Precipitation Extremes in Europe, 1946-99, J. Climate, 16, 3665-3680, doi:10.1175/15200442(2003)016<3665:TIIODT>2.0.CO;2, 2003.

Klein Tank, A. M., Zwiers, F. W., and Zhang, X.: Guidelines on Analysis of extremes in a changing climate in support of informed decisions for adaptation, World Meteorological Organization, World Climate Data and Monitoring Programme (WCDMP) series No 72, 2009.

McKee, T., Doesken, N., and Kleist, J.: The relationship of drought frequency and duration to time scales, 8th Conference on Applied Climatology, 179-184, 17-22 January 1993, Anaheim, California, 1993.

Orlowsky, B. and Seneviratne, S. I.: Elusive drought: uncertainty in observed trends and short- and long-term CMIP5 projections, Hydrol. Earth Syst. Sci., 17, 1765-1781, doi:10.5194/hess-171765-2013, 2013.

Sen, P. K.: Estimates of the Regression Coefficient Based on Kendall's Tau, J. Am. Stat. Assoc., 63, 1379-1389, 1968.

Seneviratne, S., Nicholls, N., Easterling, D., Goodess, C., Kanae, S., Kossin, J., Luo, Y., Marengo, J., McInnes, K., Rahimi, M., Reichstein, M., Sorteberg, A., Vera, C. and Zhang, X. Field, C., Barros, V., Stocker, T., Q in, D., Dokken, D., Ebi, K., Mastrandrea, M., Mach, K., Plattner, G.-K., Allen, S., Tignor, M., and Midgley, P. (Eds.): Managing the Risks of Extreme Events and Disasters to Advance Climate Change Adaptation Changes in climate extremes and their impacts on the natural physical environment, Cambridge University Press, Cambridge, 109-230, 2012.

Stahl, K., Hisdal, H., Hannaford, J., Tallaksen, L. M., van Lanen, H. A. J., Sauquet, E., Demuth, S., Fendekova, M., and Jódar, J.: Streamflow trends in Europe: evidence from a dataset of nearnatural catchments, Hydrol. Earth Syst. Sci., 14, 2367-2382, doi:10.5194/hess-14-2367-2010, 2010.

Stahl, K., Tallaksen, L. M., Hannaford, J., and van Lanen, H. A. J.: Filling the white space on maps of European runoff trends: estimates from a multi-model ensemble, Hydrol. Earth Syst. Sci., 16, 2035-2047, doi:10.5194/hess-16-2035-2012, 2012.

Stagge, J. H., Tallaksen, L. M., Gudmundsson, L., Van Loon, A. F., and Stahl, K.: Candidate Distributions for Climatological Drought Indices (SPI and SPEI), Int. J. Climatol., doi:10.1002/joc.4267, in press, 2015.

Theil, H.: A rank-invariant method of linear and polynomial regression analysis. I, II, III, P. Roy. Netherlands Acad. Sci., 53, 386392, 521-525, 1397-1412, 1950.

Ventura, V., Paciorek, C. J., and Risbey, J. S.: Controlling the Proportion of Falsely Rejected Hypotheses when Conducting Mul- 
tiple Tests with Climatological Data, J. Climate, 17, 4343-4356, doi:10.1175/3199.1, 2004.

Wilks, D. S.: On "Field Significance" and the False Discovery Rate, J. Appl. Meteorol. Climatol., 45, 1181-1189, doi:10.1175/JAM2404.1, 2006.

Yue, S. and Wang, C.: The Mann-Kendall Test Modified by Effective Sample Size to Detect Trend in Serially Correlated Hydrological Series, Water Resour. Manage., 18, 201-218, doi:10.1023/B:WARM.0000043140.61082.60, 2004.
Zhang, X., Zwiers, F. W., Hegerl, G. C., Lambert, F. H., Gillett, N. P., Solomon, S., Stott, P. A., and Nozawa, T.: Detection of human influence on twentieth-century precipitation trends, Nature, 448, 461-465, doi:10.1038/nature06025, 2007. 